\title{
Cluster del Salmón en Chile: análisis de los factores de competitividad a escala internacional
}

\author{
Vera Garnica, José*
}

\section{Resumen}

Este estudio tiene como objetivo central identificar y analizar los factores que determinan la competitividad internacional del Cluster del Salmón de Chile. La metodología utilizada es descriptiva, contrastando los enfoques teóricos planteados por Porter en los "determinantes de la ventaja competitiva de las naciones", y "las economía externas y acción conjunta" desarrollado por Schmitz. Como resultados se establece que los factores, constituidos por: condiciones naturales, bajos costos de mano de obra, y la presencia de centros educacionales especializados, tienen una importancia relevante en la competitividad del cluster. Respecto de los sectores afines y auxiliares, la red de proveedores de insumos y tecnología han fortalecido su eficiencia. La estructura del cluster se ha dinamizado con la incorporación de capitales extranjeros, fortaleciendo la innovación y la transferencia tecnológica. En cuanto a la eficiencia colectiva, producto de las economías externas y acción conjunta, está determinada por una red vigorosa de relaciones de colaboración. EI Cluster del Salmón en Chile, constituye un caso en el que se presentan elementos que fortalecen su competitividad en los mercados internacionales, producto de condiciones particulares referidas al territorio y la capacidad de producir acción conjunta.

Palabras clave: Factores de competitividad, clusters industriales, economías de aglomeración, mercados internacionales.

Recibido: 27-04-09. Aceptado: 25-06-09

Administrador Público, Universidad de Chile (1983); Magísteren Administración y Dirección de Empresas, Universidad de Santiago de Chile (1992), Doctorando en Estudios Empresariales, Universidad de Barcelona- España. Académico Departamento de Gobierno y Empresa, Universidad de Los Lagos- Chile. (jvera@ulagos.cl) 


\section{The Salmon Cluster in Chile: Analysis of Competitiveness Factors on an International Scale}

\section{Abstract}

This study aims to identify and analyze the central factors that determine the international competitiveness of the Salmon Cluster in Chile. The methodology used is descriptive, contrasting theoretical approaches raised by Porter in "Determining the Competitive Advantage of Nations" and "External Economies and Joint Action" developed by Schmitz. Results state that factors consisting of natural conditions, low labor costs and the presence of specialized educational centers play an important role in cluster competitiveness. With regard to ancillary and related sectors, the network of suppliers and technology has enhanced its efficiency. The cluster structure has been boosted with the arrival of foreign capital, strengthening innovation and technology transfer. As for collective efficiency, the result of external economies and joint action is determined by a strong network of partnerships. The Salmon Cluster Chile is a case where elements to strengthen its competitiveness in international markets are the product of particular conditions regarding the territory and the ability to produce action.

Key words: Competitiveness factors, manufacturing clusters, economies of agglomeration, international markets.

\section{Introducción}

Un interés creciente se manifiesta a partir de la década de los ochenta por la naturaleza de las aglomeraciones regionales de empresas y "clusters", más recientemente dicho interés se ha centrado en los factores subyacentes de la mejora de las ventajas competitivas de las empresas pertenecientes a esos clusters. El escenario globalizado que enfrentan las empresas pertenecientes a dichas aglomeraciones industriales ha condicionado drásticamente su forma de competir en los distintos mercados, la competitividad que se logra en el ámbito local no es suficiente, simplemente no se puede hablar de competitividad si esta no se afianza y sostiene a escala internacional.

La experiencia internacional de los clusters exitosos demuestra que el centro del éxito competitivo tiene un carácter cada vez más local. La aptitud para crear una concentración de capacidades locales, tecnología local, infraestructura local y proveedores locales en campos específicos, constituye la clave para el éxito competitivo. En la lucha generalizada por la competitividad, las agrupaciones de empresas pueden resultar especialmente favorecidas debido a su singularidad y a su potencial factor de unicidad, basado en sus capacidades locales y endógenas.

La competitividad no es resultado de la exclusiva gestión de la empresa, sino que depende de numerosas interrelaciones y alianzas entre los sistemas de valor de otras empresas e instituciones y por la calidad del ambiente local en el cual opera, por lo tanto trasciende a la empresa como unidad y la sitúa en una jerarquía industrial superior. 
De acuerdo a estas consideraciones este estudio da a conocer los factores de mayor importancia que determinan la competitividad y desarrollo del "Cluster del Salmón en Chile" a nivel internacional. Para ello se toma como referencia, diversos enfoques teóricos que se refieren a los clusters y luego se aplican y describen a la realidad del cluster del salmón en Chile.

Un primer aspecto que se estudia es la conceptualización de cluster bajo diferentes perspectivas. Un segundo aspecto en estudio es la identificación de los integrantes del cluster y su participación en él, lo que también define las fronteras del mismo. El tercer aspecto en estudio son las distintas etapas de la evolución del cluster o ciclo de vida con los cambios que ha experimentado en sus diversas fases de existencia.

El cuarto aspecto que se revisa está referido a los enfoques teóricos de "la ventaja competitiva de las naciones" y los determinantes de las fuentes competitivas en el clusters del salmón; y el enfoque "Acción conjunta y eficiencia colectiva", destacando las distintas actividades de colaboración y las instituciones de apoyo que generan la eficiencia del cluster del salmón.

\section{El fenómeno de los clusters}

Se entiende comúnmente por cluster a una "concentración sectorial y/o geográfica de empresas que se desempeñan en las mismas actividades o en actividades estrechamente relacionadas tanto hacia atrás, hacia los proveedores de insumos y equipos, como hacia adelante y hacia los lados, hacia industrias procesadoras y usuarias así como a servicios y actividades estrechamente relacionadas con importantes y acumulativas economías externas, de aglomeración y especialización (por la presencia de productores, proveedores y mano de obra especializada y de servicios anexos al sector) y con la posibilidad de llevar a cabo una acción conjunta en búsqueda de eficiencia colectiva" (Ramos, 1998).

Los clusters pueden ser entendidos también como "un conjunto de actividades similares delimitadas geográficamente, con activos canales de transacciones comerciales, comunicación y diálogo, que comparten infraestructura especializada, mercado de trabajos y de servicios, y que enfrentan oportunidades y amenazas comunes" (Rosenfeld, 1996, citado en Otero et al., 2004).

Para la OCDE (1999), los clusters son "redes de producción de empresas fuertemente interdependientes (incluyendo proveedores especializados), ligadas unas a otras en una cadena de producción que añade valor", así, "el concepto Cluster va más a allá de las redes horizontales simples, en las cuales, las empresas que operan en el mismo mercado de productos finales pertenecen al mismo grupo industrial cooperan en ciertas áreas, comprendiendo alianzas estratégicas con Universidades, Institutos de Investigación, servicios empresariales intensivos en conocimiento, Instituciones puentes (comisionistas, consultores y clientes)".

Porter (1999) denomina los "Clusters": masas críticas - ubicadas en determinado lugar de inusual éxito competitivo de determinados campos. Agrupan a una amplia gama de industrias y otras entida- 
des relacionadas que son importantes para competir. Incluyen, por ejemplo, a proveedores de insumos críticos -como componentes, maquinarias y servicios, y a proveedores de infraestructura especializada. Con frecuencia también se extienden aguas abajo hasta canales y clientes y, lateralmente, hasta fabricantes de productos complementarios y empresas que operen en industrias relacionadas por sus habilidades, tecnologías o insumos comunes. En muchas ocasiones los clusters incluyen organismos gubernamentales y otras instituciones - universidades, agencias encargadas de fijar normas, centros de estudios, proveedores de capacitación y asociaciones de comercio que proveen entrenamiento, educación, información, investigación, y apoyo técnico. Un cluster, por lo tanto, es una manera alternativa de organizar la cadena de valor.

Un concepto integrador de Cluster correspondería a la concentración progresiva de empresas de la misma industria, que con el afán de un crecimiento sostenido de ésta, mantienen relaciones de cooperación con entidades involucradas como Universidades, Gobierno, Centros de Investigación, Instituciones Financieras, Proveedores, etc. Este desarrollo es posible por el uso de las economías externas positivas que se generan sobre la base de acciones conjuntas, creando un nivel elevado de innovación y especialización mejorando de tal forma la productividad, para así obtener la ventaja competitiva requerida en determinado sector económico.

A partir de los conceptos señalados para definir a los clusters, podemos intentar destacar aspectos comunes y signifi- cativos. El patrón común está referido al conjunto de empresas afines y relacionadas por su cadena de valor, que comparten un espacio geográfico con claro potencial de eficiencia colectiva por su articulación empresarial. En su accionar se relacionan activamente no sólo con la finalidad de competir, sino que también de cooperar para añadir valor y generar ventaja competitiva al conglomerado de empresas. Lo importante no es la relación en sí entre las empresas, sino que la calidad de ella, poniéndose énfasis en las tecnologías compartidas con claras posibilidades de desarrollo e innovación.

La teoría de los clusters menciona que "ésta aboga por potenciar las concentraciones emergentes de empresas y por fomentar el desarrollo de aquellos campos que tengan lazos más fuertes con cada cluster o efectos mayores de él" (Porter, 2003). Además los trabajos enfocados en analizar la economía de los clusters se basaron principalmente en las economías de aglomeración, que establecen que los beneficios producidos dentro de un cluster se denominan economías de aglomeración, "además, definieron las economías de escala externas como el ahorro de costos de las firmas, producido por el tamaño o crecimiento del producto de la industria" (conjunto de firmas) (Weber, 1929; Hoover, 1937).

Es importante destacar que "la mayoría de los estudios teóricos de los cluster versan sobre difusión de innovaciones, que pretende conocer los factores que inciden en el desarrollo de nuevas tecnologías y del conocimiento y así poder generar un mayor crecimiento económico. Sin embargo, la mayoría de los estudios empíricos se basan en análisis de 
vínculos en la cadena de valor debido a la mayor disponibilidad de datos" (Hoen, 1999).

En este sentido, también consideran que el principal factor que impulsa los procesos de concentración espacial lo constituye el desarrollo de mano de obra, proveedores, infraestructuras e instituciones especializadas (Krugman, 1992). Así, "los cluster surgen tanto en sectores de alta tecnología como en sectores tradicionales, tanto en sectores industriales como en sectores de servicios".

En términos generales en un cluster se van desarrollando interrelaciones entre empresas e instituciones involucradas, las cuales dependiendo de su eficacia pueden fomentar dicho cluster, por lo tanto, "los cluster pueden pensarse como procesos de agregación de valor y de articulaciones verticales y horizontales, que partiendo de una actividad principal, aglutina en torno a ella un número variable de actividades" (Otero, et. al, 2004).

"Los Cluster verticales son aquellos que reúnen industrias caracterizadas por relaciones de compra-venta. Mientras que los Clusters horizontales incluyen empresas que comparten un mercado común para los bienes finales, o utilizan la misma tecnología o trabajadores, o requieren un recurso natural similar" (Porter, 2003).

\section{El ciclo de vida de los Clusters}

Todo Cluster productivo posee un ciclo de vida, que nace, se desarrolla y declina. Autores como Krugman (1992), señalan que en el origen de los Clusters encontramos frecuentemente un acci- dente, el desarrollo de los acontecimientos suele ser el siguiente: un accidente conduce a la instalación de una empresa en un lugar determinado $y$, a continuación, acontece un proceso acumulativo.

Se puede explicar también el nacimiento de un Cluster por "la formación de las primeras empresas, por la existencia de una reserva de factores, por trabajadores especializados, expertos investigadores universitarios, una ubicación física favorable, o una infraestructura especialmente buena o apropiada. Igualmente los Cluster pueden surgir como consecuencia de una demanda local inusual, informada o exigente. También surgen por la previa existencia de sectores proveedores, y gracias a la existencia de una o dos empresas innovadoras que estimulen el crecimiento de muchas otras" (Porter, 2003).

Otros autores como Espinoza (2003), menciona que la generación de los clusters se debe principalmente a tres tipos de condiciones. La primera la denomina Creación espontánea y se genera de forma natural en torno a algún núcleo natural con ventajas comparativas o competitivas. En su formación no existen esfuerzos declarados por traer empresas y las ventajas provienen de la ubicación y no de la relación. La segunda forma en que se pueden generar la identifica como Creación artificial por privados, donde, a partir del esfuerzo de alguna empresa o conjunto de ellas, han identificado beneficios potenciales de crear un sistema de relaciones comerciales. En tanto la Creación artificial de gobierno se constituye en una iniciativa auspiciada, financiada y generalmente coordinada por parte del gobierno (local o nacional), en el cual se ha 
descubierto una nueva área de crecimiento y desarrollo económico no reconocido por los privados, y que por lo tanto no están dispuestos a financiar. Generalmente en este caso los beneficios son más bien sociales (generación de empleo, reducción de la pobreza, etc.).

En un cluster viable surgen proveedores especializados, la información se acumula, las instituciones locales desarrollan planes de formación especializada, y las labores de investigación e infraestructura mejoran.

Los estudios de diversos casos indican que los Cluster necesitan diez años o más para adquirir real madurez y conseguir verdadera ventaja competitiva. "A este respecto, las ventajas que ofrecen los Cluster para la creación de nuevas empresas son diversas; las barreras de entrada son menores, los inversores e instituciones financieras locales están familiarizados ya con este tipo de actividades, existe un mercado local" (Porter, 1998) Hay tres áreas que merecen especial atención: la intensidad de la competencia local, el clima general del lugar para la formación de nuevas empresas, y la eficiencia de los mecanismos formales e informales de unión entre los integrantes del Cluster, y todo esto puede afectar también al Cluster incrementando la productividad de las empresas o sectores que los integran; incrementando la capacidad de innovar y, con ello, su capacidad de aumentar la productividad, fomentando así ventajas en la competencia" (Porter, 2003).

Los Clusters pueden conservarse por años incluso por siglos, "las causas que pueden ocasionar la decadencia de un Cluster se agrupan en dos categorías generales: endógenas, originarias de la propia ubicación, y exógenas, debida a los acontecimientos o cambios del medio exterior. Las causas interiores de decadencia derivan de rigideces internas que disminuyen la productividad y la capacidad de innovación. La aparición de reglas sindicales restrictivas o de leyes inflexibles puede frenar la mejora de la productividad. El exceso de fusiones, pactos, carteles u otras limitaciones de la competencia pueden socavar la rivalidad local. Las instituciones de enseñanza pueden adolecer también de rigidez y pueden dejar de mejorar y evolucionar.

Estas rigideces suelen surgir en lugares en los que el Estado es proclive a suspender la competencia o a entrometerse en ella. Las amenazas externas pueden ser de varios tipos; la evolución tecnológica quizá sea la más significativa, porque puede neutralizar simultáneamente varias ventajas del Cluster. Puede dejar desfasadas la información sobre el mercado, la cualificación de los empleados, la pericia científica, técnica y la cartera de proveedores. Un cambio en las necesidades de los compradores que dé lugar a una estrategia entre las necesidades locales y las necesidades existentes en otros lugares constituye otra amenaza externa a la productividad y capacidad de innovación de un Cluster" (Porter, 2003).

Por su parte Espinoza (2003) indica que, existen tres etapas que pueden explicar los principales factores que conforman el estancamiento de un cluster. La primera etapa la identifica como Saturación del mercado objetivo. En esa fase no existen suficientes potenciales compradores como para hacer la inversión rentable. Como segunda etapa señala que se 
constituye cuando un Mercado de insumos insuficiente, por tanto, no existen suficientes productores de insumos dentro del cluster como para permitir la producción de bien en cuestión. Los costos de comprar a proveedores externos eliminan las ventajas frente a los productores internos. Finalmente la Disminución de los beneficios de "conectarse" se explica cuando llegado un punto, las economías externas de la red no serán suficientes en magnitud como para compensar los efectos en el sistema de la empresa entrante.

Habría que indicar que "algunos Clusters experimentan un renacimiento o recuperación con un nuevo conjunto de industrias. Esto puede suceder por varias razones. En primer lugar, por el simple juego del mecanismo de precios: los viejos Clusters, con abandonadas instalaciones, suelen ser también los más baratos. La política de renovación urbana puede intentar, asimismo, hacer revivir a Cluster moribundos, pero es la posibilidad de convergencia (o efectos transsectoriales) de viejas y nuevas tecnologías, las que pueden hacer que los Clusters maduros vuelvan a ser atractivos para ubicarse, por ejemplo, las compañías maduras en industrias tradicionales, que están empezando a explotar el potencial de las tecnologías" (Swann, 1998).

En definitiva, la prueba de fuego de un cluster es su ritmo de innovación. Un cluster que invierte e innova en su lugar de asentamiento tiene mucho menos motivos de preocupación que uno que mejora su productividad exclusivamente a base de reducir su volumen y subcontratar actividades.

\section{El modelo de la ventaja competitiva de las naciones}

En el trabajo "The Competitive Advantage of Nations" de Porter (1990), se hace referencia a los efectos que tiene la ubicación en la competencia, la cual ha sido entendida como fundamentalmente estática y basada en la minimización de los costos. Sin embargo, esta concepción no refleja la realidad de la competencia, la competencia es dinámica y se basa en la innovación y en la búsqueda de ventaja competitiva.

Al respecto, Porter elaboró un modelo del efecto que tiene la ubicación en la competencia, para lo cual consideró cuatro elementos interrelacionados que representó gráficamente en forma de rombo. Resulta conveniente destacar los elementos de esta estructura para comprender la función de los Cluster en la competencia.

Las Condiciones de los factores que se define en torno a la situación de los factores; los activos tangibles (como la infraestructura material), la información, la calidad y costos de los recursos naturales, recursos humanos, etc. Los factores especializados, sobre todo los que resultan esenciales para la innovación (por ejemplo, un instituto universitario o un Centro de investigación especializada), no sólo fomentan un nivel elevado de productividad, sino que suelen ser más difíciles de obtener o adquirir en otros lugares.

Por su parte las Condiciones de la demanda determinan la posibilidad que las empresas pasen de ofrecer productos y servicios de imitación y baja calidad, a basar su oferta en la diferenciación. Para 
avanzar es necesario que se desarrolle un mercado nacional cada vez más exigente. La presencia o aparición de clientes avanzados y exigentes en el mercado nacional obliga a las empresas a mejorar y les permite apreciar las necesidades existentes y las que van apareciendo. La demanda interior también puede poner de manifiesto segmentos de mercado en los cuales las empresas puedan diferenciarse. En una economía mundial, la calidad de la demanda interior importa mucho más que su dimensión.

Los Sectores afines y auxiliares son el tercer determinante, y dice relación con la presencia de sectores afines y auxiliares que sean internacionalmente competitivos, éstos crean ventajas competitivas en varios aspectos. Primero, suministran los recursos más económicos y lo hacen de un modo eficaz, rápido y, algunas veces, preferente. Los proveedores y usuarios finales situados cerca unos de otros (Cluster), pueden sacar provecho de unas líneas de comunicación cortas, de un flujo de información rápida y constante y de un intercambio permanente de ideas e innovaciones. Las empresas tienen la oportunidad de influir en los esfuerzos técnicos de sus proveedores y pueden servir de lugares de ensayo para la labor de I\&D, acelerando el ritmo de innovación. La competitividad interior en los sectores afines proporciona ventajas similares; el flujo de información y el intercambio técnico aceleran la velocidad de la innovación.

El Contexto para la estrategia y la rivalidad de las empresas se refieren, básicamente, a las reglas e incentivos y normas que rigen el tipo y la intensidad de la rivalidad interior. En las economías que tienen un nivel bajo de productividad hay poca rivalidad y poca inversión. Si hay competencia los rivales nacionales tienden a imitarse entre sí. La evolución de una economía más avanzada requiere una rivalidad interior vigorosa. La rivalidad debe pasar de la reducción de los salarios a la reducción del costo total, para lo que es necesario mejorar la eficiencia en la producción. En última instancia, la rivalidad también debe dejar de estar centrada en el costo, para centrarse en la diferenciación. La competencia debe pasar de la imitación a la innovación y de la inversión baja a la inversión cuantiosa en activos, no sólo material, sino también inmaterial.

El contexto de la estrategia y la rivalidad se refiere a dos aspectos: primero, el entorno en el que se produce la inversión en sus diversas formas. La estabilidad macroeconómica y política sienta las bases del contexto en el que se produce la inversión, pero también influyen las políticas microeconómicas: la estructura del sistema fiscal, el sistema de gobierno, etc. $Y$ el segundo aspecto corresponde a la apertura al comercio exterior y a la inversión extranjera, la presencia de empresas públicas, las reglas de concesión de licencias, la política antimonopolista, la influencia de la corrupción, entre otras cosas determinan la intensidad de la rivalidad interior.

En el Diagrama 1 se detallan los cuatro puntos del diamante de Porter:

\section{Acción conjunta y eficiencia colectiva}

Según Schmitz (1997), los conceptos de Economías Externas y Acción 


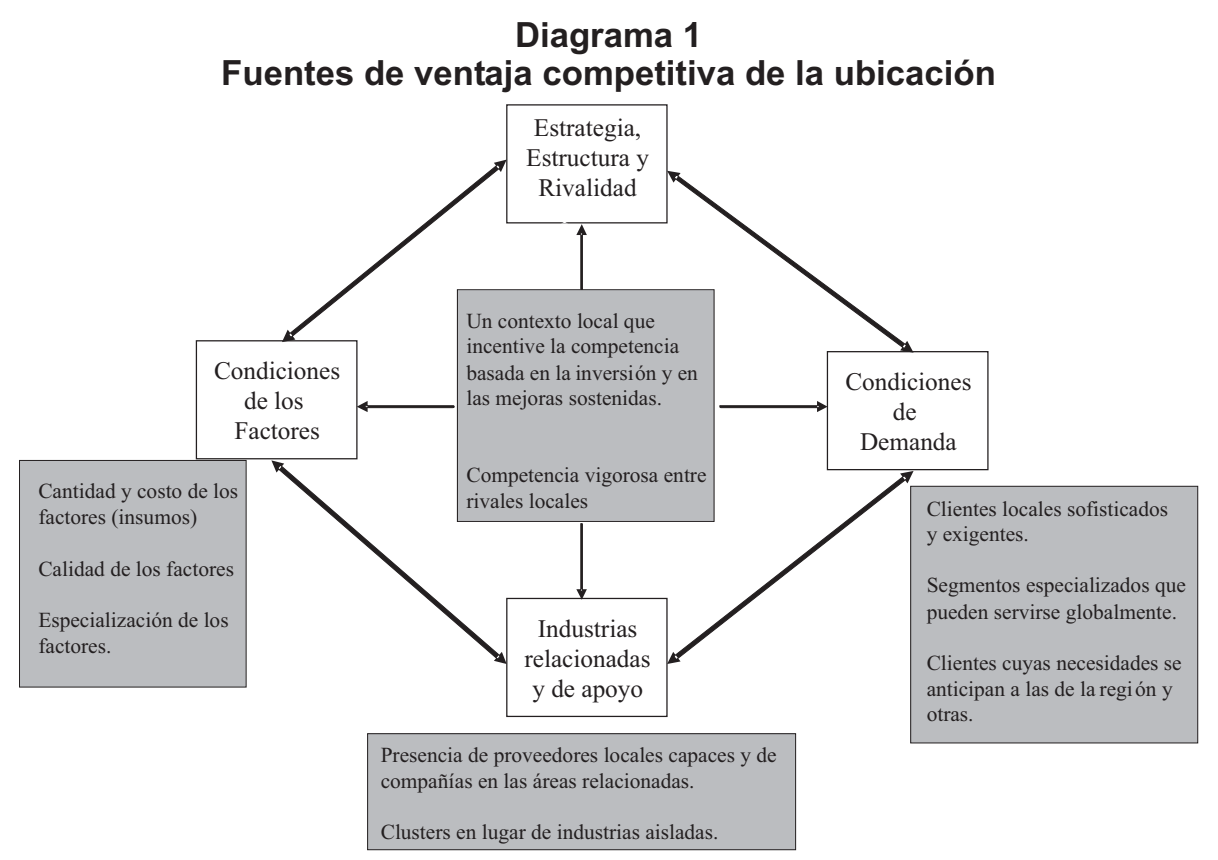

Fuente: Porter (2003).

Conjunta, explican de manera consistente el nacimiento y expansión que han experimentado varios Clusters alrededor del mundo. De allí surge el concepto global de "Eficiencia Colectiva", que distingue dos conceptos iniciales: Economías externas positivas y La Acción Conjunta.

Las Economías externas positivas (o eficiencia colectiva pasiva) son ahorros que una empresa puede realizar debido al accionar de otros actores. Estos surgen cuando los actores no pueden incorporar todos los costos y beneficios de una actividad. Por ejemplo: cuando el resultado de una investigación o una inversión en capital humano "se derrama" hacia otras empresas. Economías externas no necesariamente requieren una concentración geográfica, pero la cercanía física de los actores complementarios sue- le facilitar la actividad. El problema, sin embargo, es que dicho concepto está restringido a ganancias o pérdidas no planificadas. Por lo tanto, los efectos no planificados son de gran importancia en el desarrollo de los Clusters contemporáneos, pero, de acuerdo a las investigaciones realizadas en varios países, ellos son también producto de acciones y decisiones planificadas por parte de los agentes económicos. Esto último es lo que se denomina "Acción Conjunta".

La Acción Conjunta (o eficiencia colectiva activa),en tanto, actúa como medida deliberada, incluyendo la asociación con otros interesados para velar por los intereses del gremio, intercambiar informaciones o contratar un servicio compartiendo los costos. Esta Acción Conjunta puede darse directamente entre dos 0 
más empresas o bien a través de asociaciones gremiales e instituciones de fomento.

La mayoría de los autores comparte este énfasis en la Eficiencia Colectiva, agregando en las definiciones algunos elementos de externalidades y Acción Conjunta; por ejemplo se refieren a las externalidades positivas que resultan de una oferta local de mano de obra calificada en una determinada actividad. También observan vinculaciones hacia adelante y hacia atrás entre las empresas que integran el Cluster conformándose en un en un tejido industrial, los intercambios intensivos de información entre empresas, instituciones e individuos en el Cluster, dan lugar a un ambiente creativo e innovador lo cual también es resaltado como otra característica de estos conglomerados. Las diferentes acciones en conjunto destinadas a generar ventajas competitivas para las empresas locales, en conjunto con el desarrollo de instituciones de fomento que ofrecen servicios especializados para las empresas y un cierto grado de coherencia socio-cultural (valores compartidos y confianza mutua) que facilitan la cooperación son elementos que resaltan adicionalmente como atributos de los Clusters.

Tal Acción Conjunta puede ser de dos tipos, cooperación de firmas indivi- duales (por ejemplo compartiendo equipo o desarrollando un nuevo producto) y grupos de firmas que juntan fuerzas en asociaciones comerciales, consorcios productivos, entre otros (ver Cuadro 1).

\section{Integrantes del Cluster del Salmón en Chile}

Se identifican en el Cluster del Salmón los integrantes más relevantes de la cadena productiva conformadas por empresas privadas, en su mayoría proveedoras de insumos, materias primas, maquinarias y accesorios, que tienen relevancia en el proceso de agregación de valor a los procesos productivos. Se consideran también a entidades públicas que tiene un rol regulador de la actividad, de fomento productivo, de investigación e innovación, etc. Se consideran, además, los distintos grupos de interés (Stakeholders) involucrados. Todos estos integrantes se representan en el Diagrama 2.

Las empresas productoras de salmón que conforman el cluster son actores de gran importancia productiva que mantienen estrechas relaciones cooperativas y de confianza sin que ello signifique renunciar a una fuerte rivalidad. Estas empresas productoras corresponden en su mayoría a empresas de capitales extranjeros. En el año 1994 existían unas 100

\section{Cuadro 1 \\ Formas de Acción Conjunta}

\begin{tabular}{lll}
\hline & \multicolumn{1}{c}{ Bilateral } & \multicolumn{1}{c}{ Multilateral } \\
\hline Horizontal & Ej. Compartiendo equipos & Ej. Asociaciones sectoriales \\
Vertical & Ej. Productores y usuarios que & $\begin{array}{l}\text { Ej. Alianzas entre cadenas de valor } \\
\text { mejoran componentes }\end{array}$ \\
\end{tabular}

Fuente: (Otero et al., 2004). 


\section{Diagrama 2 \\ Integrantes del Cluster del Salmón}

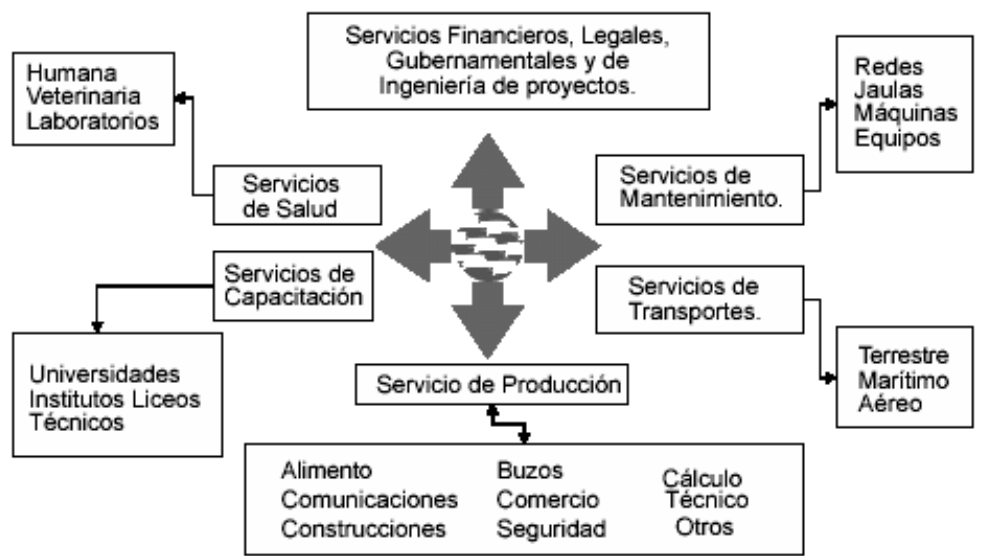

Fuente: Salmonchile, 2008.

empresas procesadoras, al 2008 operan unas 49, aproximadamente. Esto se debe sobre todo al proceso de fusiones y adquisiciones iniciada en la etapa de globalización, donde se originó una tendencia por parte de las empresas más grandes del cluster a integrar los procesos de la producción, mencionando por ejemplo: el caso de la multinacional de origen holandés Nutreco, que compró inicialmente la empresa de alimentos para peces Biomaster, propiedad del grupo lansa, después Marine Harvest en el cultivo de salmones, originalmente propiedad de capitales escoceses, adquiriendo luego al mayor productor local, Pesquera Mares Australes (Montero, 2004).

Luego en el año 2005 Marine Harvest tomó participación mayoritaria en las salmoneras noruegas Pan Fish y Fjord Seafood, con lo que se convirtió en la principal productora mundial de salmónidos, con un total cosechado de aproximadamente 420.000 toneladas en el 2007, lo que representa más de un $25 \%$ de la producción mundial.

A esto se agregan las compras realizadas el 2005 por AquaChile que adquirió el 99,9\% de Aguas Claras, además del $69 \%$ de Salmones Chiloé, el 99\% de Salmones Australes (todas productoras locales) y el $60 \%$ de Robinson Crusoe, empresa de origen europeo (Pérez, 2007).

Posteriormente la compañía Coloso también productora nacional informó en el año 2006 la creación de la empresa Salmones Humboldt en conjunto con empresarios ligados al sector salmonicultor, cuya producción alcanzó más de 20.000 toneladas.

Finalmente en Mayo del 2007 AquaChile adquirió el $40 \%$ restante de la división Salmones de Robinson Crusoe dando origen a una nueva empresa: Salmones Maullín S.A, que funciona como una unidad de negocios independiente dentro del grupo (Revista Aqua 2007). 
Las empresas de mayor tamaño integran el proceso completo, desde la producción de Ovas hasta la comercialización, manteniendo un alto nivel de inversión, básicamente en investigación y desarrollo. Se puede nombrar como las empresas de mayor tamaño en el Cluster a Marine Harvest, AquaChile, Mainstream, Multiexport y Salmones Antártica.

Las empresas medianas utilizan sus recursos basándose en la eficiencia, tratando de aumentar sus volúmenes de producción y llevando a cabo estrategias de cooperación para aprovechar los beneficios de este Cluster, como es el caso de Aguas Claras, Invertec, entre otras. Fi- nalmente las empresas más pequeñas hacen lo posible para mantenerse en un ambiente de alta competitividad.

En la Tabla 1 se muestra las primeras empresas del Cluster, de acuerdo a toneladas por exportación.

Uno de los Stakeholders más importantes en el Cluster del Salmón corresponde a las empresas proveedoras que tienen como finalidad proveer de todos los insumos (100 prestadoras de insumos), servicios (400 empresas de servicios), etc. a las empresas productoras del Cluster, concentrándose en él aproximadamente unas 500 empresas proveedoras dirigidas a cumplir con los diferen-

\section{Tabla 1}

\section{Principales empresas exportadoras año 2008}

\begin{tabular}{|c|c|c|}
\hline Exportador & $\begin{array}{c}\text { Cantidad } \\
\text { (T. Netas) } \\
2008\end{array}$ & $\begin{array}{c}\text { Valor (miles de } \\
\text { US } \$ \text { FOB) } \\
2008\end{array}$ \\
\hline MARINE HARVEST CHILE S.A. + DELFISH LTDA & $15.351,11$ & $79.111,62$ \\
\hline $\begin{array}{l}\text { EMPRESAS AQUA CHILE S.A. (Aqua Chile S.A. +Salmones } \\
\text { Chiloé S.A. +Salmones Maullín Ltda. +Aguas Claras S.A.) }\end{array}$ & $19.108,60$ & $77.284,39$ \\
\hline CIA PESQUERA CAMANCHACA S.A & $7.895,77$ & $53.503,76$ \\
\hline MAINSTREAM CHILE S.A & $11.145,41$ & $50.682,93$ \\
\hline $\begin{array}{l}\text { SALMONES MULTIEXPORT S.A (Perteneciente a Multiexport } \\
\text { Foods S.A) }\end{array}$ & $5.951,34$ & $36.612,27$ \\
\hline CULTIVOS MARINOS CHILOE S.A & $4.364,76$ & $29.449,38$ \\
\hline PESQUERA LOS FIORDOS LTDA. & $7.622,95$ & $26.314,81$ \\
\hline TRUSAL S.A. & $6.583,21$ & $24.924,29$ \\
\hline SALMONES ANTARTICA S.A & $5.659,20$ & $24.051,01$ \\
\hline CULTIVOS YADRAN S.A. & $4.871,72$ & $22.361,77$ \\
\hline SALMONES PACIFIC STAR LTDA. & $3.840,92$ & $20.161,84$ \\
\hline PESCA CHILE S.A. & $4.370,42$ & $20.129,01$ \\
\hline Otros Exportadores & $41.984,40$ & $170.968,02$ \\
\hline TOTAL & $138.749,81$ & $635.555,10$ \\
\hline
\end{tabular}

Fuente: Elaboración de Aqua a partir del Informe estadístico y de Mercado de SalmonChile. 
tes requerimientos de las productoras en todas las fases de producción: empresas dedicadas a la construcción de jaulas, proveedoras de alimentos, fabricación de redes, proveedoras de equipos e insumos para la producción en mar y procesos, insumos farmacéuticos y laboratorios, servicios logísticos, envases y embalajes, proveedoras de ovas, etc. Uno de los factores importantes a destacar corresponde a la existencia de Pequeñas y medianas empresas (Pymes) locales proveedoras del Cluster, las que se han incorporado facilitando el acceso directo a los insumos y servicios y, además, sustituyendo la importación de tecnologías. El $71 \%$ de las empresas proveedoras de la industria del salmón son de capitales exclusivamente nacionales lo que favorece a las empresas existentes en el país.

La existencia de diversas empresas proveedoras en la Xy XI regiones del país, ha fomentado la concentración progresiva de empresas en el Cluster. Por ejemplo, existen 5 proveedoras de alimentos, cuatro transnacionales extranjeras (Nutreco de Holanda que posee un $33 \%$ de participación en Chile), (Ewos de Finlandia representa el 33\%), (Biomar de Dinamarca que ocupa un $10 \%$ en participación), y (Alitec del grupo Povimi de Holanda que representa un 14\%), y una empresa chilena (Salmofood que cubre el 10\% en nuestro país). Otro hecho es que la mayoría de las maquinarias utilizadas en el proceso son importadas desde Noruega y Escocia. Al igual que inicialmente las ovas eran importadas desde Escocia, Irlanda, Noruega, Dinamarca y Estados Unidos.

En el caso de la importación de ovas, se puede apreciar que éstas han ido dismi- nuyendo en el transcurso del tiempo por causa de las enfermedades originadas por estas importaciones, actualmente la producción nacional está a cargo del Instituto de Fomento Pesquero (IFOP) y por privados. Actualmente existen unas 29 empresas proveedoras de ovas, 22 de alevines y 22 de Smolts.

SalmonChile, asociación gremial que agrupa a las principales empresas productoras y proveedoras de la industria del salmón en Chile sumó el 2008 a nuevos socios, se trata de cuatro empresas productoras de salmones: Cultivos Marinos Chiloé Ltda., River Fish S.A., Aquaterra Araucanía Ltda. y Cultivos Ecofish S.A. Cabe destacar que Cultivos Marinos Chiloé S.A. representó el año 2007 el $5,5 \%$ de los envíos nacionales. De este modo, SalmonChile congrega a $83 \mathrm{em}$ presas, de las cuales 35 son proveedoras y 49 productoras (Candia, 2008).

En cuanto a la interacción de las instituciones de gobierno, estas se relacionan con el Cluster ya que su misión de fomento de las actividades productivas del país así lo demanda. En este sentido el gobierno ha impulsado la articulación de esfuerzos público-privados posibilitando la generación de políticas públicas orientadas al desarrollo de la actividad; igualmente impulsa la inversión conjunta en investigación y desarrollo.

Los centros universitarios, Institutos y Liceos Técnicos forman los profesionales que se desempeñan en la industria, y desarrollan actividades de perfeccionamiento para potenciar las capacidades de los recursos humanos. Las universidades regionales tales como la Universidad Austral y la Universidad de Los La- 
gos tienen un rol destacado en ello. En otro ámbito, los centros de investigación cumplen la función de implementar nuevos proyectos referentes a Investigación y Desarrollo que impulsan la innovación y el aprendizaje tecnológico para así lograr la eficiencia esperada en el Cluster.

Las entidades financieras también forman parte del Cluster del Salmón. Se estima que el financiamiento total bancario en la industria del salmón en Chile fluctúa entre los US\$1.500 y US\$1.600 millones. Esta cifra considera la deuda suscrita con la banca que opera en Chile, sin incluir el financiamiento que reciben, al menos en parte, las empresas cuyas casas matrices se localizan en otros países (Vargas 2008).

\section{Ciclo de vida del Cluster del Salmón en Chile}

La identificación del ciclo de vida se torna interesante, por el hecho de poder detectar las causas más relevantes que han influido en los cambios del Cluster del Salmón en todas sus etapas de desarroIlo, según Maggi (2002) el ciclo de vida del Cluster del Salmón consta de tres etapas claramente diferenciadas. Al extrapolar estas etapas al caso chileno se puede precisar que la etapa de Aprendizaje Inicial (1978-1985) se da lugar al surgimiento del Cluster del Salmón, que se caracterizó por el aprovechamiento de las ventajas naturales en la región de los Lagos, y comienzan a aparecer las primeras empresas dedicadas a la producción de salmones. Este período trasciende por el hecho de lograr las primeras 1.000 toneladas de exportación, pero es sólo en el año 1980 cuando Chile se incorpora al grupo mundial de países exportadores de Salmón. El desafío de esta etapa fue lograr la supervivencia de los peces, lo que trajo consigo todo un afán de cooperación por parte de organismos públicos y privados, destacándose la creación en 1986 de la Asociación de Productores de Salmón y Trucha de Chile, con la finalidad de cooperar en dos temas fundamentales: comercialización y sello de calidad.

En el año 1974 la empresa norteamericana Unión Carbide, a través de su filial Domsea Farms Chile, inició su producción a partir de ovas importadas en Curaco de Vélez en la Isla de Chiloé, iniciativa que no dio resultado por factores climáticos, y que no posibilitaron nuevas inversiones. Luego en el año 1981, Fundación Chile compró Domsea Farms, y se convirtió en Salmones Antártica, que fue la primera empresa en superar las 1.000 toneladas exportadas. Esta etapa pasó por grandes dificultades, como por ejemplo, el proceso productivo en general no contaba con las condiciones de especialización requerida tanto en tecnología, como en los proveedores existentes.

En tanto en la etapa de Expansión (1986-1995) se evidenció un fuerte aumento de los volúmenes de producción, por lo que fue necesario incrementar la especialización tanto en la tecnología utilizada como en los demás factores, por lo que ciertas empresas optaron por eslabonamientos hacia atrás, adquiriendo pisciculturas especializadas para mejorar su proceso y unificar estándares de calidad que requería el mercado internacional. Las empresas proveedoras, por su lado, comienzan a profesionalizarse para enfrentar un entorno cada vez más competitivo. 
Un hecho relevante consistió en la creación del canal asociativo de productores nacionales Salmoexport, integrado por 13 empresas salmoneras nacionales con el objetivo de iniciar una ardua gestión de marketing, dando a conocer los productos nacionales, y con esto, lograr llegar a nuevos nichos de mercado. Luego, en el año 1995, se creó el Instituto tecnológico del Salmón (Intesal), que nació con el objetivo de ser un centro de investigación científica para proveer de avances y tecnología a la industria del salmón en Chile, relacionándose con universidades y centros de investigación del mundo, encargado de contribuir técnicamente a posicionar el salmón chileno en los consumidores y grupos de interés relacionados con la industria, como un bien saludable, seguro, y ambientalmente sustentable.

Finalmente, dos acontecimientos culminaron con la etapa de expansión: la acusación de Dumping por parte de Estados Unidos, y la crisis asiática que ocasionó una caída de los precios internacionales por la sobreoferta producida entre los años 1988 a 1993: La solución recaía en reducir los costos para poder aumentar la producción.

La última etapa de Globalización (de 1996 en adelante) se vio marcada por el ingreso de empresas de gran tamaño, principalmente de capitales extranjeros, lo que ocasionó la desaparición de empresas pequeñas y la absorción por parte de estas grandes empresas frente a las Pymes. Esta etapa se caracterizó por una acelerada integración en el proceso productivo y el establecimiento de alianzas estratégicas que facilitaron el mayor acceso a tecnología y trabajar sobre la base de la eficiencia aplicada en todas las fa- ses productivas para obtener la calidad y el valor agregado que requería el producto, lo cual hizo posible la diversificación de los productos y la captación de nuevos mercados.

Desde el año 2002 la industria comienza una etapa de consolidación a través de diversas iniciativas político-gremiales impulsadas por SalmonChile e INTESAL respectivamente.

Se hizo necesario también implementar políticas públicas que regularan el manejo medio ambiental y que garantizaran la difusión de buenas prácticas; establecer acuerdos de transferencia tecnológicas y optar por una mayor inversión en I\&D (por ejemplo, la biotecnología), que ha jugado un rol fundamental en el crecimiento de la industria del salmón a lo largo de sus más de 20 años. En efecto, la actividad de cultivo de salmón fue un hecho innovador desde sus inicios, a comienzos de los 80 , que ha requerido de nuevas innovaciones para adaptarse a la realidad nacional y a un mercado mundial cada vez más competitivo y exigente (ver Cuadro 2).

\section{Fuentes de ventaja competitiva en el Cluster del salmón en Chile}

El Cluster del Salmón está conformado por un conjunto de factores que hacen posible su existencia; recursos naturales disponibles, la ubicación geográfica, etc. Destacando también que el Cluster del Salmón se ha caracterizado por que su desarrollo ha sido provocado por un afán de aprendizaje colectivo de todos los involucrados. Todas estas variables se identifican en el modelo de Porter, mo- 


\section{Cuadro 2 \\ Ciclo de Vida del Cluster del Salmón en Chile}

\begin{tabular}{|c|c|c|c|}
\hline & $\begin{array}{c}\text { Aprendizaje Inicial } \\
\text { (desde 1978) }\end{array}$ & $\begin{array}{c}\text { Maduración } \\
\text { (desde } 1986 \text { hasta 1995) }\end{array}$ & $\begin{array}{c}\text { Globalización } \\
\text { (desde } 1996 \text { en adelante) }\end{array}$ \\
\hline Hitos & $\begin{array}{l}\text { - Transferencia y } \\
\text { Adaptación Tecno- } \\
\text { lógica }\end{array}$ & $\begin{array}{l}\text { - Aumento escala a nivel } \\
\text { comercial }\end{array}$ & $\begin{array}{l}\text { - Acusación de Dumping } \\
\text { - Fusiones e Integraciones } \\
\text { - Nuevas regulaciones } \\
\text { - SIGES, APL, PTI }\end{array}$ \\
\hline $\begin{array}{l}\text { Objetivo } \\
\text { principal }\end{array}$ & $\begin{array}{l}\text { - Supervivencia de } \\
\text { los peces }\end{array}$ & $\begin{array}{l}\text { - Aumentar volúmenes de } \\
\text { producción } \\
\text { - Asociatividad y especiali- } \\
\text { zación }\end{array}$ & $\begin{array}{l}\text { - Diversificación y penetración } \\
\text { de mercados y productos } \\
\text { - Aumentar el valor de la cade- } \\
\text { na productiva } \\
\text { - Cooperación pública-privada }\end{array}$ \\
\hline $\begin{array}{l}\text { Mercado de } \\
\text { destino }\end{array}$ & $\begin{array}{l}\text { - Producto: Coho (pa- } \\
\text { cífico) fresco. } \\
\text { - Mercado: elite }\end{array}$ & $\begin{array}{l}\text { Producto: Coho en forma } \\
\text { de HG a Japón. } \\
\text { - Mercados: Japón }\end{array}$ & $\begin{array}{l}\text { Producto filetes y porciones } \\
\text { a EE.UU. } \\
\text { Mercados diversificados } \\
\text { como: Japón, EE.UU, nichos } \\
\text { Europa y mercados emer- } \\
\text { gentes }\end{array}$ \\
\hline $\begin{array}{l}\text { Canales de } \\
\text { comercialización }\end{array}$ & $\begin{array}{l}\text { - Venta directa y coo- } \\
\text { perativas }\end{array}$ & $\begin{array}{l}\text { - Brokers. } \\
\text { Canal asociativo de pro- } \\
\text { ducción nacionales (sal- } \\
\text { moexport) }\end{array}$ & $\begin{array}{l}\text { - Mayoristas (supermercados) } \\
\text { gracionzas estratégicas o inte- } \\
\text { cados de destino. }\end{array}$ \\
\hline $\begin{array}{l}\text { Imperativo } \\
\text { tecnológico }\end{array}$ & $\begin{array}{l}\text { - Pisciculturas Experi- } \\
\text { mentales } \\
\text { - Know how en En- } \\
\text { gorda }\end{array}$ & $\begin{array}{l}\text { Eslabonamientos hacia } \\
\text { atrás (piscicultura) } \\
\text { - Certificación de calidad } \\
\text { - Aumento escala de Pro- } \\
\text { ducción. }\end{array}$ & $\begin{array}{l}\text { - Producción nacional de ovas. } \\
\text { - Eslabonamiento hacia delan- } \\
\text { te (proceso) } \\
\text { - Control ciclo de desarrollo } \\
\text { del salmón } \\
\text { - Sistemas de control automa- } \\
\text { tizado de parámetros (agua, } \\
\text { luz, etc.) } \\
\text { - Vacunas y alimentos } \\
\text { - Sustentabilidad del sistema }\end{array}$ \\
\hline $\begin{array}{l}\text { Políticas } \\
\text { públicas }\end{array}$ & $\begin{array}{l}\text { - Regulación } \\
\text { - Transferencia de } \\
\text { tecnología } \\
\text { - Inversión } \\
\text { - Investigación pre- } \\
\text { competitiva }\end{array}$ & $\begin{array}{l}\text { - Infraestructura } \\
\text { - Promoción y marketing } \\
\text { (misiones) } \\
\text { - Innovación y desarrollo } \\
\text { tecnológico } \\
\text { - Proveedores (jaulas, re- } \\
\text { des, alimentos) }\end{array}$ & $\begin{array}{l}\text { - Manejo medioambiental } \\
\text { - Aumento de productividad y } \\
\text { transferencia de tecnología } \\
\text { (misiones tecnológicas) } \\
\text { - Biotecnología (enfermedades } \\
\text { y manejo genético) }\end{array}$ \\
\hline
\end{tabular}




\section{Cuadro 2 (Continuación)}

\begin{tabular}{|c|c|c|c|}
\hline & $\begin{array}{c}\text { Aprendizaje Inicial } \\
\text { (desde 1978) }\end{array}$ & $\begin{array}{c}\text { Maduración } \\
\text { (desde } 1986 \text { hasta 1995) }\end{array}$ & $\begin{array}{c}\text { Globalización } \\
\text { (desde } 1996 \text { en adelante) }\end{array}$ \\
\hline $\begin{array}{l}\text { Tipo de empresa } \\
\text { en el núcleo del } \\
\text { Cluster }\end{array}$ & $\begin{array}{l}\text { Pequeña y mediana } \\
\text { empresa }\end{array}$ & $\begin{array}{l}\text { - Pequeña y mediana em- } \\
\text { presa } \\
\text { - Presencia de grupos ex- } \\
\text { tranjeros }\end{array}$ & $\begin{array}{l}\text { - Grandes empresas (integra- } \\
\text { ción y concentración) }\end{array}$ \\
\hline $\begin{array}{l}\text { Tipo de empresa } \\
\text { proveedora del } \\
\text { Cluster }\end{array}$ & $\begin{array}{l}\text { Pocas y precarias. } \\
\text { - Empresas tienden a } \\
\text { autoabastecerse de } \\
\text { requerimientos }\end{array}$ & $\begin{array}{l}\text { Mayor outsoursing, em- } \\
\text { presas locales que se } \\
\text { profesionalizan. }\end{array}$ & $\begin{array}{l}\text { - Pymes locales especializa- } \\
\text { das. } \\
\text { - Presencia significativa de } \\
\text { empresas altamente espe- } \\
\text { cializadas. }\end{array}$ \\
\hline Externalidades & - Efecto demostración & $\begin{array}{l}\text { - Acceso a proveedores } \\
\text { - Masa crítica }\end{array}$ & - Difusión de buenas prácticas \\
\hline $\begin{array}{l}\text { Factor } \\
\text { competitivo } \\
\text { empresarial }\end{array}$ & $\begin{array}{l}\text { Producción: Lograr } \\
\text { la engorda e iniciar } \\
\text { las primeras expor- } \\
\text { taciones. }\end{array}$ & $\begin{array}{l}\text { - Calidad: Unificar están- } \\
\text { dares de calidad. } \\
\text { - Encadenamiento hacia } \\
\text { atrás. } \\
\text { - Refuerzo I\&D }\end{array}$ & $\begin{array}{l}\text { - Eficiencia: costo del salmón } \\
\text { cosechado } \\
\text { - Innovación tecnológica e I\&D } \\
\text { en genética } \\
\text { - Desarrollo de vacunas, logís- } \\
\text { tica. }\end{array}$ \\
\hline $\begin{array}{l}\text { Capital social } \\
\text { Entorno }\end{array}$ & $\begin{array}{l}\text { Esfuerzos pioneros } \\
\text { públicos y privados. }\end{array}$ & $\begin{array}{l}\text { Asociatividad entre pro- } \\
\text { ductores }\end{array}$ & $\begin{array}{l}\text { - Sistema productivo inserto } \\
\text { en cadena global de produc- } \\
\text { ción-comercialización. } \\
\text { - Cooperación público-privada } \\
\text { local. } \\
\text { - Fortalecimiento del capital } \\
\text { social. }\end{array}$ \\
\hline
\end{tabular}

Fuente: Elaboración propia a partir de Maggi, Montero, Parra, (2000) y Bañados, Alvial (2006).

delo que explica que la ubicación afecta directamente a la ventaja competitiva y tiene efectos trascendentales en la producción y la innovación. Al extrapolar estas variables al caso Chileno se traduce en que Las Condiciones de los Factores de mayor relevancia que han condicionado al Cluster del Salmón corresponden a la existencia de ciertas ventajas comparativas, como por ejemplo: costos bajos de mano de obra en la región que se destacan a nivel mundial. Otro de los factores que ha posibilitado el nacimiento del
Cluster del Salmón corresponde a las ventajas naturales; medio ambiente y disponibilidad de insumos, como por ejemplo: condiciones hidrográficas favorables, adecuada temperatura de las aguas, centros de abastecimiento de insumos alimentarios cercanos como la harina de pescado, luz natural aún en invierno, etc. (Maggi, 2002). Todos estos factores constituyen fuentes de economías externas.

Sin embargo, la tecnología aplicada posee una baja especialización en 
comparación con otros competidores internacionales, ya que todavía maquinarias de gran utilización en el proceso productivo deben ser importadas, a pesar de ello la infraestructura material en las plantas procesadoras son de buenas condiciones. En este sentido, las pisciculturas por ejemplo, se han ido tecnificando cada vez más, lo cual ha sido fundamental para apoyar la etapa inicial de producción de salmones.

También la existencia de instituciones educacionales especializadas fomenta la formación de profesionales y técnicos calificados en diferentes áreas de interés del Cluster del Salmón. A pesar de ello es importante otorgar mayor especialización a los factores requeridos, como la baja calidad de los laboratorios de investigación, débil apoyo del sistema financiero, dificultad en el acceso a información especializada (Larroulet y Durán, 2005), los cuales deben ser mejorados para seguir con la sustentabilidad del Cluster en los próximos años.

En las Condiciones de la Demanda, se evidencia, una demanda interna relativamente baja por el hecho que los consumidores no tienen una preferencia por los productos del mar. En este sentido, es indispensable establecer una "imagen país" que posicione el producto a nivel nacional e internacional, destacando las características nutritivas del Salmón. Es importante para el Cluster aumentar el consumo interno de Salmón, ya que esto puede tener efectos positivos de imagen derivada de la demanda frente a los mercados internacionales. De todas formas la industria salmonera destina sus productos de preferencia a mercados extranjeros, donde la intensidad de la compe- tencia es vigorosa, y en los cuales la línea de productos ofertados se caracteriza por su elevada calidad y el valor agregado incorporado a ellos, de los cuales se puede encontrar una variedad de productos que se comercializan de acuerdo a los requerimientos de cada mercado.

En cuanto a los Sectores afines y auxiliares tienen como característica su identificación en la región-sur del país correspondiente a la masa crítica de empresas proveedoras existentes, las que en parte han hecho posible el buen desempeño y mejoramiento de las actividades. La existencia de empresas proveedoras extranjeras ubicadas en el Cluster del Salmón ha facilitado la oferta de una amplia gama de insumos, tecnología especializada, etc. $Y$ además, las empresas proveedoras nacionales han podido aprender de la experiencia de las empresas extranjeras para especializarse aún más.

La apertura comercial también ha permitido que la difícil obtención de maquinarias especializadas sea posible, pero aún faltan empresas proveedoras especializadas para hacer que el proceso de desarrollo sea más satisfactorio, mencionando, por ejemplo, la escasez de empresas proveedoras de servicios, encargadas del área financiera, de transporte, etc. (Larroulet y Durán, 2005).

La existencia de sectores afines hace que el Cluster se vea fortalecido, ya que en conjunto pueden dar soluciones a ciertas carencias de esta concentración, estableciendo nuevas iniciativas dirigidas a un mayor flujo de información, intercambio técnico, y una preocupación constante por innovar. De igual forma, el número de empresas proveedoras ha au- 
mentado significativamente a lo largo del tiempo, creándose en el Cluster nuevas empresas de acuerdo a las necesidades de éste, como es el caso de la producción de ovas, que inicialmente eran importadas, pero luego, se llevó a cabo la producción nacional de éste, mejorando la entrega directa de las ovas a las empresas salmoneras del Cluster.

Dentro del escenario competitivo en el Cluster del Salmón las Estructuras, estrategias y rivalidad de empresas se caracteriza por un afán de cooperación de las empresas inmersas en él. En este sentido, en el Cluster existe una alta inversión, tanto por parte de empresas extranjeras como nacionales. Por otro lado, esta concentración se caracteriza por un elevado grado de cooperación y rivalidad a la vez, aprovechando las economías externas generadas en el Cluster, lo cual se refleja en todas las dimensiones del diamante.

La ardua competitividad que surge en el Cluster del Salmón, da origen a una preocupación constante por innovar, sobre la base de altos índices de inversión, lo que ha favorecido también el aumento de la productividad de las empresas que conforman el Cluster, beneficiando con esto la creación de nuevas empresas.

Se puede destacar que las empresas productoras del Cluster del Salmón han impulsado una serie de esfuerzos e interrelaciones con los demás integrantes del Cluster para generar los beneficios necesarios y aumentar así su crecimiento, por ejemplo, el aprovechamiento de ciertas medidas para el mejoramiento de las buenas prácticas tanto en calidad como en medio ambiente. La Asociación de Productores de Salmón y Trucha A. G. tiene real importancia en las acciones emprendidas en el Cluster, ya que ésta agrupa un gran número de empresas tanto productoras como proveedoras del Cluster del Salmón como objeto de unión y cooperación en diferentes actividades relacionadas al surgimiento de éste.

El rol del Gobierno es de gran importancia en este punto del diamante, ya que la finalidad de éste es apoyar constantemente el desarrollo del Cluster del Salmón, en este sentido, se puede mencionar la apertura comercial de Chile frente a los mercados internacionales, las medidas regulatorias sobre la protección del recurso natural y la agilización del proceso de obtención de concesiones marítimas. Sin embargo, falta establecer una política de Cluster en Chile que se encargue de solucionar las barreras impuestas, para que el desarrollo del Cluster se mantenga y se incremente aún más.

\section{Eficiencia colectiva en el Cluster del salmón en Chile}

Hay una gran discusión respecto a los factores que dieron origen a la formación del cluster del salmón en la región. La rápida y exitosa expansión de la industria se le puede atribuir a una combinación entre ventajas comparativas naturales y capacidades competitivas adquiridas, las que también son denominadas economías externas naturales y adquiridas. Por tanto entre las Economías Externas naturales y adquiridas caben destacar:

Recursos Naturales: La existencia de un escenario óptimo para salmonicultura como condiciones hidrográficas, oxi- 
genación y temperaturas de las aguas, con una velocidad de renovación suficiente, ayuda de alguna manera a la calidad de los productos acuícola.

Medio Ambiente: La lejanía de centros poblados, aguas libres de contaminación y disponibilidad de luz natural, ayuda a la región a introducir especies de otros países. Esto es gracias a una latitud más ecuatorial que la de los centros productivos en el norte de Europa.

Disponibilidad de insumos: La cercanía de centros de abastecimientos de insumos alimenticios y energéticos para el cultivo (harina y aceite de pescado). Permite que las empresas asociadas al cluster disminuyan sus costos de transporte.

Las ventajas comparativas no tienen valor si no se saben aprovechar. A la dotación de recursos hay que agregarles las capacidades adquiridas como se muestra a continuación:

Recursos Humanos: Esto se debe a la disponibilidad de profesionales universitarios emprendedores y dispuestos a participar en proyectos de alto riesgo, inicialmente atraídos desde la zona central del país, pero en forma paulatina durante los años siguientes, se fueron formando profesionales en la región, debido a la adecuación de la oferta curricular de las universidades y centros de formación establecidos localmente.

Regulación y apoyos públicos: Existió, desde la partida, un marco jurídico, administrativo y económico que no constituyó un obstáculo para la rápida masificación de la actividad. La autoridad pública definió un sistema de adjudicación de concesiones marítimas litorales que, si bien fue criticado en sus inicios, abrió el mercado a nuevos agentes. A ellos siguió el apoyo público en materia sanitaria, comercialización y transferencia tecnológica.

Iniciativa empresarial: Existencia de capacidades empresariales y profesionales, capaces de visualizar las oportunidades de desarrollo futuro de la actividad, y asumir el riesgo inicial. Dichas capacidades se fueron potenciando hasta adquirir, en algunos casos, la talla necesaria para competir a nivel mundial.

Asociatividad: Capacidad de organización colectiva, para conformar la Asociación de Productores de Salmón y Trucha, hoy en día llamada Asociación de la Industria del Salmón, entidad que asumió iniciativas relevantes como la gestión frente a las autoridades para la implantación de normas regulatorias.

Aprendizaje tecnológico: Esto se debe al desarrollo progresivo de capacidad local para cubrir todos los eslabones de la cadena de valor hacia atrás (producción nacional de ovas) y hacia delante (procesamiento), gracias al aprovechamiento de condiciones favorables en zonas relativamente cercanas.

Desarrollo de oferta local de insumos y servicios claves a estándares competitivos: alimentos, vacunas, balsas-jaula, transporte marítimo, etc.

Al momento de asegurar la existencia de un Cluster se debe tener muy en claro, primero, la existencia de Instituciones de Apoyo, junto a la presencia de economías externas y acciones conjuntas, por lo que en este apartado se mencionarán algunos de los esfuerzos conjuntos más trascendentes que se han llevado a cabo en el Cluster del Salmón, para lo cual es primordial determinar las Instituciones de apoyo vinculadas al 
Cluster. Las empresas e instituciones involucradas en el Cluster del Salmón, mantienen distintas relaciones tanto verticales (de proveeduría), horizontales (de las empresas procesadoras de Salmón) y relaciones transversales (referentes a cooperación de instituciones complementarias en el Cluster del Salmón), de lo cual se puede inferir que sobre la base de estas relaciones se generan beneficios para todos los integrantes de este Cluster.

Las Instituciones de Apoyo se dividen en: Instituciones Reguladoras, Instituciones de Fomento, e Instituciones de Capacitación. Las primeras cumplen con el objetivo de la expansión productiva, siempre y cuando estas medidas sean adoptadas con las prácticas adecuadas. Actualmente las Instituciones reguladoras son: Servicio Nacional de Pesca (SERNAPESCA), Dirección Regional de Concesiones del Territorio Marítimo (DIRECTEMAR), Comisión Nacional del Medio Ambiente (CONAMA), Comisión de Borde Costero

Todas estas controlan y aprueban actividades relacionadas con el desarrollo de la salmonicultura, por ejemplo; La CONAMA es la institución del Estado que tiene como misión promover la sustentabilidad ambiental del proceso de desarrollo y coordinar las acciones derivadas de las políticas y estrategias definidas por el Gobierno en materia ambiental. De igual forma, se destacan estrechas relaciones transversales, entre la industria procesadora de Salmón y las instituciones en materia regulatoria. En general, las empresas privadas han sido colaboradoras, tomando conciencia de la importancia de tomar medidas para controlar y regular a la industria en sus actividades.
Por otro lado, las Instituciones de Fomento asignan recursos a proyectos de promoción y desarrollo tecnológico e investigación, y a su vez, existen instituciones que ejecutan estos proyectos. Las que destinan recursos a proyectos son: Subsecretaría de Pesca, Corporación de Fomento (CORFO), Programa de Fomento a las Exportaciones Chilenas (PROCHILE), Gobierno Regional, Comisión Nacional de Investigación Científica y Tecnológica (CONYCIT).

Estas entidades financian proyectos a través de fondos concursables, y por otro lado, las Instituciones que ejecutan estos proyectos corresponderían a: Instituto de Fomento Pesquero (IFOP), Universidades, Fundación Chile, Asociación de Productores de Salmón y Trucha A.G. (SalmonChile), Comisión Nacional de Investigación Científica y Tecnológica (CONICYT)

Finalmente, las Instituciones de Capacitación se encargan de dar inicio a la implementación de cursos de capacitación en áreas de interés para el Cluster con el objeto de otorgar la formación adecuada a los recursos humanos. Las instituciones encargadas de esta formación serían: Universidad Austral, y Universidad de Los Lagos, Institutos profesionales y Centros de formación técnica, Instituto Tecnológico del Salmón (INTESAL), Servicio Nacional de Capacitación y Empleo (SENCE).

De acuerdo a información entregada por el SENCE de la X Región, durante el año 2005 la industria del salmón realizó un total de 1.866 acciones de capacitación, que se tradujeron en una inversión tanto pública como privada de US\$ 1,8 millones. 
El gasto total en $I+D$ realizado en el Cluster del Salmón en el período 1990-2006 supera los US\$ 76 millones. Estos aportes han sido financiados de manera conjunta entre el sector privado y público. En efecto, un $49,8 \%$ ha sido aportado por el Gobierno, mientras que un $43,2 \%$ corresponde al sector privado y el $7 \%$ restante proviene de los programas realizados por INTESAL (Quiroz, 2006).

Entre el 2006 y 2007 el clúster del salmón ha sido capaz de capturar recursos de Innova Chile programa implementado por CORFO en montos que ascienden a MM\$20.000, los que sumados al aporte empresarial hace que esta industria de manera histórica se destinen cerca de MMUS\$ 90 (Infante, 2008).
Las Acciones Conjuntas se refieren a la eficiencia colectiva lograda en el Cluster del Salmón ha sido posible a la capacidad de relaciones estrechas de cooperación colectiva entre los integrantes, el aprendizaje tecnológico en componentes de poca especialización, la gran oferta de insumos y servicios requeridos en el Cluster, la formación de un recurso humano calificado, etc. En el Cuadro 3 se detallan algunas de las acciones conjuntas llevadas a cabo por los participantes del Cluster del Salmón:

Algunas de las acciones conjuntas han sido ya efectuadas y los resultados han sido favorables, y otras aún están en curso. A continuación se explican con mayor detalle algunas de las principales Acciones Conjuntas realizadas:

\section{Cuadro 3}

\section{Acciones conjuntas realizadas en el Cluster del Salmón}

\begin{tabular}{|c|c|c|c|c|}
\hline Etapa & $\begin{array}{l}\text { Accion Colectiva y } \\
\text { Actores Envueltos }\end{array}$ & Causa/Incentivo & Financiamiento & Resultados \\
\hline $\begin{array}{l}\text { Aprendizaje } \\
\text { Inicial }\end{array}$ & $\begin{array}{l}\text { Productores } \\
\text { nacionales: } \\
\text { Formación } \\
\text { Salmoexport }\end{array}$ & $\begin{array}{l}\text { Validación en } \\
\text { mercados de destino, a } \\
\text { través de sello de } \\
\text { calidad a productos } \\
\text { exportados. }\end{array}$ & $\begin{array}{l}\text { Privado (90\%) Aportes } \\
\text { empresas, apoyos } \\
\text { indirectos vía } \\
\text { Fundación Chile. } \\
\text { (US\$ M150/año) }\end{array}$ & $\begin{array}{c}\text { Satisfactorios. Acción } \\
\text { finaliza al cabo de } 4-5 \\
\text { años, una vez } \\
\text { posicionado Chile como } \\
\text { oferente mundial. }\end{array}$ \\
\hline $\begin{array}{l}\text { Aprendizaje } \\
\text { inicial/ } \\
\text { Maduración }\end{array}$ & $\begin{array}{l}\text { APSTCH: } \\
\text { Cooperación con } \\
\text { entidades } \\
\text { reguladoras para } \\
\text { establecimiento dist. } \\
\text { mínima entre } \\
\text { concesiones para } \\
\text { cultivos, y estándares } \\
\text { procesamiento }\end{array}$ & $\begin{array}{c}\text { Favorecer } \\
\text { sustentabilidad de la } \\
\text { actividad. Evitar erosión } \\
\text { de ventajas } \\
\text { comparativas. }\end{array}$ & $\begin{array}{l}\text { Privado (100\%) } \\
\text { Aportes empresas } \\
\text { miembros de la } \\
\text { Asociación. }\end{array}$ & $\begin{array}{c}\text { Adecuados, la industria } \\
\text { cumple las normas. }\end{array}$ \\
\hline Maduración & $\begin{array}{l}\text { APSTCH y ProChile: } \\
\text { Campañas de } \\
\text { promoción del } \\
\text { consumo de salmón } \\
\text { en EE.UU. en conjunto } \\
\text { con productores Alaska } \\
\text { y Canadá. También en } \\
\text { otros mercados. }\end{array}$ & $\begin{array}{l}\text { Desarrollo de } \\
\text { mercados }\end{array}$ & $\begin{array}{c}\text { Público/Privado }(50 / 50) \\
\text { ProChile y aportes } \\
\text { empresas. Canalizados } \\
\text { por la Asoc. (US\$ } \\
\text { M600) }\end{array}$ & $\begin{array}{l}\text { Óptimos. La tasa de } \\
\text { crecimiento del } \\
\text { consumo en EE.UU. } \\
\text { se ha mantenido por } \\
\text { sobre el } 20 \% \text { anual. } \\
\text { Sin embargo, } \\
\text { campañas se } \\
\text { descontinuaron en } \\
1997 .\end{array}$ \\
\hline
\end{tabular}




\section{Cuadro 3 (Continuación)}

\begin{tabular}{|c|c|c|}
\hline Etapa & $\begin{array}{l}\text { Accion Colectiva y } \\
\text { Actores Envueltos }\end{array}$ & Causa/Incentivo \\
\hline Maduración & $\begin{array}{c}\text { APSTCH: Formación } \\
\text { del Instituto } \\
\text { Tecnológico del } \\
\text { Salmón, INTESAL } \\
(1994)\end{array}$ & $\begin{array}{l}\text { Desarrollo de } \\
\text { capacidades locales, } \\
\text { para el desarrollo y la } \\
\text { transferencia } \\
\text { tecnológica. }\end{array}$ \\
\hline
\end{tabular}

Maduración, globalización

\section{Globalización}

APSTCH: Defensa
colectiva frente a
acusaciones de
dumping.

Globalización

$$
\begin{gathered}
\text { INTESAL, Empresas, } \\
\text { Univ. Austral: } \\
\text { Programa de } \\
\text { monitoreo }
\end{gathered}
$$

empresas para efectuar

Globalización Fundación Chinquihue, Presentación asociativa INTESAL, Empresas,

Universidades regionales:

Formulación

Programa Chile

Califica, para la obtención de financiamiento público

$\begin{array}{ccc}\text { Globalización } & \text { SalmonChile, } & \text { Favorecer } \\ & \text { Universidades, } & \text { sustentabilidad de la } \\ \text { Gobierno: Firma } & \text { actividad. Evitar erosión } \\ \text { Acuerdo Voluntario } & \text { de ventajas } \\ \text { Medioambiental } & \text { comparativas. }\end{array}$
Califica, para otorgar y

Financiamiento Resultados

Público/Privado (70/30) Regulares. A pesar de Corfo-Fontec, y haber contado con un canaliza aportes importante apoyo empresas. la Asoc. público, empresas (US\$ M1000, para privilegian los partida y dos años de desarrollos apropiables, operación inicial) por lo que INTESAL ha operado básicamente como entidad de capacitación laboral.

Público/Privado Importantes. Salmofood (20/80\%), empresas se ha posicionado envueltas, con apoyo a como el único oferente la partida de Corfo nacional de alimento -Fontec para I+D. para salmones.

Actualmente el control mayoritario es ejercido por una empresa.

Satisfactorios. La adecuada defensa industria. Gobierno colabora con gestiones logró que gravámenes de apoyo. US\$M400. aplicados fuesen bajos.

INTESAL y un grupo de

Universidad Austral

(Sede Puerto Montt), monitoreos preventivos de agentes tóxicos en

áreas de cultivo

Público/Privado (50/50\%), apoyados por Fondef-Conicyt, con el equipamiento instrumental. US\$ M150/año.

Público/Privado (70/30\%), programa para la acreditación de gubernamental Chile certificar competencias laborales de operarios

y técnicos de una industria.

$$
\begin{gathered}
\text { competencias } \\
\text { laborales. (US\$ } \\
\text { M100/año) }
\end{gathered}
$$

Operación reciente. Importante número de empresas colabora activa-mente con la iniciativa.
Postulación seleccionada. En fase de inicio.
Suscrito en Dic. 2002: iniciándose.

Fuente: Elaboración propia a partir de Maggi (2002) y Bañados, Alvial (2006). 
Junto a INTESAL, el Gobierno y la Industria ha desarrollado desde 1990 una serie de proyectos de innovación que han permitido que la industria se posicione junto a Noruega como el mayor productor de salmones del mundo.

A nivel del Estado, se dictaron algunas normativas como el reglamento ambiental de la acuicultura (RAMA) que establece criterios uniformes que permiten verificar las condiciones de los sitios donde se realizan las debidas actividades, para su posterior seguimiento y evaluación.

También se dio inicio el Acuerdo de Producción Limpia (APL), por medio de iniciativas tanto públicas como privadas. Este se creó en el año 2002, involucra a 10 instituciones del Estado y a 48 empresas con actividad de cultivo y procesamiento de salmones en la $\mathrm{X}$ y $\mathrm{XI}$ regiones del país, su objetivo es avanzar en un pro- ceso eficiente de producción y de prevención de contaminantes. La CONAMA ha seguido impulsando este acuerdo a todo el Cluster del Salmón.

En el año 2003 se creó el Sistema Integrado de Gestión (SIGES), a partir del cual se firmó un acuerdo entre 7 empresas e INTESAL con el propósito de implementar un proyecto que implicaba la estandarización de los sistemas productivos a lo largo de toda la cadena de valor productiva de la Industria del Salmón, enfocados a 3 aspectos de vital importancia en el mundo globalizado: calidad, salud de peces y producción; medio ambiente; salud y seguridad ocupacional. Actualmente existen 24 empresas adscritas a SIGES, lo que representa un $90 \%$ de los productores asociados a SalmonChile y un $80 \%$ de la producción nacional total (en toneladas netas) (Quiroz, 2006). En el Diagrama 2 se exponen los Fundamen-

\section{Diagrama 2}

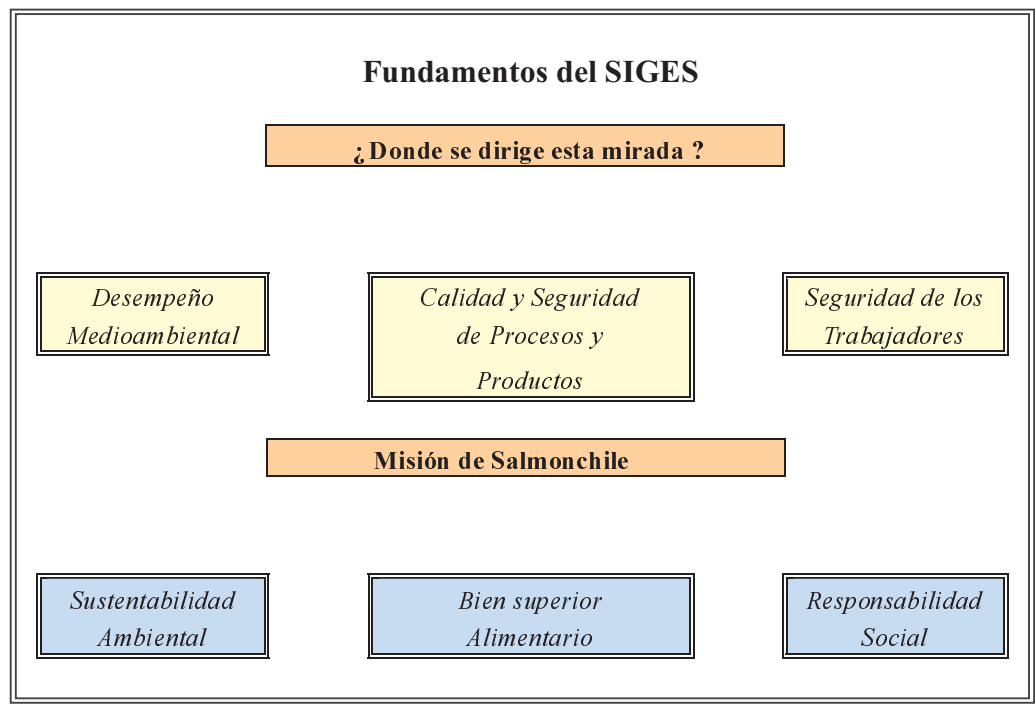

Fuente: Salmonchile, 2006. 
tos generales del SIGES, destacando sus principales funciones.

Algunos de los objetivos del SIGES implica que esta herramienta se aplique a la industria como a un todo, que logre la estandarización de conductas y procesos en aspectos normativos y de buenas prácticas en los ámbitos calidad, salud de peces y producción; medio ambiente; salud y seguridad ocupacional, adaptables y flexibles a la realidad de cada empresa.

A nivel gremial, SalmonChile ha desarrollado acciones con el objeto de fomentar la cooperación y fortalecer los lazos de confianza entre los distintos agentes involucrados al interior del cluster. Adicionalmente, ha dirigido iniciativas orientadas a la construcción de capital social y la formación educacional y laboral en la X y XI Regiones. A modo de ejemplo, cabe señalar la participación conjunta entre SalmonChile, INTESAL y el programa Chile Califica, con el objeto de desarrollar un único sistema estandarizado de certificación de competencias labores en diversos subsectores del cluster.

INTESAL y las universidades han proseguido sus esfuerzos por aumentar la cantidad y cobertura de diversos cursos de capacitación que dicta el organismo, dando origen a un curso de inglés orientado a lograr que la industria chilena del salmón se transforme en una industria bilingüe y que se inserte de manera apropiada en el mundo globalizado. También se han firmado convenios con Universidades para entregar a los trabajadores y ejecutivos de la industria una amplia oferta de cursos de capacitación, como es el caso del diplomado en habilidades directivas impartido a fines del 2004 por la Universidad de Chile, y que pretende mejorar diversos aspectos de la administración al interior de las empresas salmoneras del Cluster (Revista Aqua, 2004).

El Programa Territorial del Cluster de Salmón (PTI) se propone en el año 2005 como una instancia de coordinación público - privada, financiada por CORFO y dirigida por INTESAL de SalmonChile, la cual busca proponer y generar alternativas de solución para aquellos puntos críticos de la cadena de valor que afectan la competitividad de la industria. Para dicho efecto, el PTI cuenta con cuatro lineamientos estratégicos: focalizar los recursos públicos hacia los puntos críticos de la cadena de valor de salmón, fortalecer la base empresarial de los proveedores, aportar a la actualización de la base normativa, y detectar espacios para la realización de proyectos de I\&D y las oportunidades de inversión (Bañados, F. y Alvial, A, 2006).

Se pueden mencionar muchos otros acuerdos de cooperación que se basan en acciones conjuntas, pero todas están enfocadas en un afán de crecimiento mutuo, donde las áreas de mayor interés en este momento siguen siendo las orientadas a capacitar a los trabajadores, incentivar las buenas prácticas relacionadas con el medio ambiente, incrementar los proyectos en investigación y desarrollo referente a nuevas tecnologías, basadas por ejemplo: en medicamentos para enfermedades que atacan a los salmónidos e investigaciones genéticas, fomentar también el mejoramiento de implementos, equipos o maquinarias especializadas que favorezcan el buen desempeño de los procesos, desarrollar el mercado interno, internacionalizar las fuentes de financiamiento, buscar nuevos merca- 
dos internacionales y posicionar una "imagen país" del producto.

Los desafíos más significativos que se avizoran para el cluster del salmón están relacionados a cuatro elementos centrales.

El primero corresponde al desplazamiento de la salmonicultura hacia la XI Región de Aysén y su incidencia en los proyectos de inversión, la infraestructura asociada, y el acceso a mano de obra calificada. El segundo se relaciona con la integración de la producción y los servicios asociados, y un fortalecimiento de la cooperación a nivel de industria como una estrategia que permita mejorar los niveles de confianza, fortaleciendo el concepto de cluster como herramienta estratégica para mejorar la competitividad. El tercero, implica analizar los desafíos comerciales producto de las economías de diversificación en el marketing, la distribución, las nuevas tendencias en el retail y las exigencias de los mercados internacionales (Bañados, F. y Alvial, A, 2006).

Finalmente, se puede apreciar, que son muchos los desafíos que presenta el Cluster del Salmón actualmente, de todas formas se están tomando las acciones necesarias para apoyarlo. Tanto el sector privado como el sector público están conscientes que sobre la base de unión y cooperación se pueden aprovechar las externalidades positivas que se generan, y con esto, mantener y mejorar las ventajas que posee y se esperan en el Cluster del Salmón.

\section{Conclusiones}

La competitividad de los clusters está determinada en buena medida por la capacidad de sus integrantes de interrelacionarse activamente entre sí en materias que resultan clave para su eficiencia. La colaboración que se extienda a otros organismos públicos y privados que apoyen la cadena de producción se debe potenciar, sólo así los clusters se pueden internacionalizar y competir con las exigencias que el mercado exige.

La fase de globalización en que se encuentra el cluster del salmón en Chile es una confirmación de la eficiencia aplicada a los procesos productivos, lo que le ha permitido obtener mejor calidad y valor agregado al producto y con ello la captación de nuevos mercados internacionales.

Al aplicar el modelo de la ventaja competitiva de M. Porter se concluye que la condición de los factores, como las condiciones naturales, los bajos costos de mano de obra, y la presencia de centros educacionales especializados, tienen una mayor preponderancia. Los sectores afines y auxiliares, constituidos fundamentalmente por una red de proveedores de insumos y tecnología han fortalecido en los últimos años la competitividad del cluster. La estructura del cluster y la rivalidad presente en él se han acrecentado con la incorporación de capitales extranjeros, fortaleciendo la inversión y la innovación.

El enfoque de economías externas y acción conjunta que determinan la eficiencia colectiva del cluster del salmón, está claramente determinado por una red vigorosa de relaciones de colaboración de carácter vertical, horizontal, y transversales, con presencia de proveedores, empresas procesadoras, e instituciones complementarias del cluster. 
Desde la etapa inicial de aprendizaje del cluster se han concretado actividades de cooperación con entidades reguladoras; campañas de promoción del consumo del salmón en mercados externos en conjunto con entidades públicas; actividades de desarrollo y perfeccionamiento de los recursos humanos; acuerdos de conservación medioambiental; $y$ programas de investigación y transferencia tecnológica, que han tenido un impacto significativo en la competitividad internacional del cluster del Salmón de Chile, constituyéndose en la actualidad en el segundo productor de salmón a nivel mundial, y el primero en trucha.con una línea de productos con valor agregado dirigido a los mercados más exigentes del mundo.

El Cluster del Salmón a pasado a ser uno de los más grandes a nivel nacional, ya que la mayor parte de la actividad se concentra en una sola región. Esta concentración geográfica de compañías, instituciones, oferentes especializados, proveedores de servicios asociados disminuyen los costos de transacción, y por ende, mejoran la competitividad a escala internacional, consolidándose como el cluster basado en recursos naturales de mayor progreso competitivo en América Latina.

\section{Referencias bibliográficas}

Bañados, Felipe y Alvial, Adolfo (2006). Desafíos en la Consolidación del Cluster del Salmón Chileno: Contribución del Programa Territorial Integrado (PTI), Chile.

Candia, Jaime (2008). SalmonChile suma a cuatro nuevos socios. Documento obtenido en Internet (www.tiempo21. $\mathrm{cl} /$ loslagos/index.php?option $=\mathrm{com}$ content\&task=view\&id=577\&/temid= 5 - ), con fecha Septiembre del 2008.

Espinoza, Hugo (2003). Clusters: Teoría y Desarrollo, Facultad de Ciencias Económicas y Administrativas, Escuela de Economía y Administración. Documento obtenido en Internet (http: /www.cybertesis.cl/tesis/uchile/2003/ espinoza_h/html/index-frames.html), con fecha Agosto 2005.

Hoover, Edgar (1937). Spatial price discrimination. Review of Economic Studies, 4.

Hoen, Alex (1999). Three variations on identifying clusters, en Navarro, Mikel (2002) El análisis y la política de Clusters.

Infante V. Rodrigo, SalmonChile A.G, (2008), El Cluster del Salmón: Un aporte a la competitividad. Documento obtenido en Internet (http://www.salmonchile.cl/files/El\%20cluster\%20del\% 20salmón\%2017-09-08.ppt\#284,1, Diapositiva 1), con fecha Octubre del 2008

Krugman, Paúl (1992). Geografía y Comercio. Barcelona: Antoni Bosch editor.

Larroulet, Cristián y Durán, Felipe (2005). X Región de Los Lagos: Chile ya posee un Cluster. Informe CIEN de la Universidad del Desarrollo. Santiago, Marzo 2005.

Maggi, Claudio (2002). Cadenas productivas: lecciones de la experiencia internacional y regional. El cluster del cultivo y procesamiento del salmón en la región sur-austral de Chile. AGORA' 2000, Cooperación Técnica (BID-fomin Trust Fund Italiano).

Montero, Cecilia (2004). Formación y desarrollo de un cluster globalizado: el caso de la industria del salmón en Chile. Serie Desarrollo Productivo CEPAL No 145. 
Organización para la Cooperación y el Desarrollo Económico (1999). Managing Nacional Innovation Systems. París OCDE.

Otero, Gerardo; Lódola, Agustín y Menéndez, Lisandro (2004). El rol de los Gobiernos subnacionales en el fortalecimiento de Clusters productivos, Ministerio de Economía, Gobierno de la Provincia de Buenos Aires, Argentina. Documento obtenido en Internet (www.ec.gba.gov.ar/GIE/Investigacion/Archivos/Abril2004.pdf), con fecha agosto 2006.

Pérez, Soledad (2007). El maratonista, Alfonso Márquez de la Plata Cortés. Documento obtenido en Internet (http: //www.capital.cl/reportajes-y-entrevistas/el-maratonista-alfonso-mrquez-de-la-plata-cort-s.html) con fecha Octubre del 2008.

Porter, Michael (1990). The Competitive Advantage of the Nations, The Free Press.

Porter, Michael (1998). Clusters and the new economics of competition, Harvard Business Review

Porter, Michael (1999). Cúmulos y Competencia. Nuevos objetivos para Empresas, Estados e Instituciones, en Ser Competitivo, Nuevas aportaciones y conclusiones, Deusto, Bilbao.

Porter, Michael (2003). Ser competitivo. Nuevas aportaciones y conclusiones. Ediciones Deusto, Bilbao. pp.203288.

Quiroz, Jorge (2006), SalmonChile A.G, Informe Económico Salmonicultura 2006, pp 35-46, Documento obtenido en (www.salmonchile.cl). Con fecha Octubre del 2008.

Ramos, Joseph (1998). Una estrategia de desarrollo a partir de los complejos productivos en torno a los recursos naturales. Revista CEPAL No66.
Revista Aqua (2004). Nuevos desafíos, marzo 2004, No85

Revista Aqua (2007). Empresas AquaChile adquiere totalidad de Robinson Crusoe Salmones. Documento obtenido en Internet (http://www.aqua.cl/noticias/ index.php?doc=17726). Octubre 2008.

Revista Aqua (2009) Estadísticas de Exportación del Salmon 2008-2009. Documento Obtenido en Internet (http:// www.directorioaqua.com/contenido/ pdf/Acuicola/Exportaciondesalmonidos/Enero_febrero_2008_2009.pdf) Marzo 2009.

Rosenfeld, Simon (1996). Overachievers, Business Clusters that Work: Prospects for Regional Development, Chapel Hill, NC. Regional Technology Strategies, en Otero et. al. (2004) El rol de los gobiernos subnacionales en el fortalecimiento de Clusters productivos.

Schmitz, Hubert (1997). Collective Efficiency and increasing returns. IDS working paper 50, University de Sussex, Reino Unido.

Swann, G.M.P. (1998). Towards a Model of Clustering in High-Technology Industries. En Swann, G.M.P., Prevezer, M y Stout, D. The Dynamics of industrial clustering. International Comparisons in Computing and Biotechnology ( $p p$ 52.76) Oxford. Oxford University Press.

Vargas, Benjamín (2008). Las fortalezas de la industria en Chile permanecen intactas. Documento obtenido en Internet (http://www.aqua.cl/noticias/index. php?doc=27015) con fecha Septiembre 2008.

Weber, A. (1929). Theory of the Location of Industries. Trans. C.J. Friedrich. Chicago: University of Chicago Press. 